NOTE: This is a preprint / authors' copy.

Final version: DOI: https://doi.org/10.1007/978-3-030-18020-1 7

Cite as: Whittle J., Ferrario M.A., Simm W. (2020) Community-University Research: A Warts and All Account. In: Chamberlain A., Crabtree A. (eds) Into the Wild: Beyond the Design Research Lab. Studies in Applied

Philosophy, Epistemology and Rational Ethics, vol 48. Springer, Cham.

\title{
Community-University Research: A Warts and All Account
}

Jon Whittle, Maria Angela Ferrario, and Will Simm

\begin{abstract}
Although the traditional cliché of a University is an ivory tower where researchers hide away from the outside world, in reality, many researchers actively engage with user groups outside the University, and, by so doing, they hope to maximize the impact of their research. Many models and methodologies for achieving this exist - ranging from action research and participatory design to co-production; at their heart, they all involve getting out of the University and interacting with nonacademics in the hope that research will therefore be more relevant. But carrying out research with and within non-academic communities can be extremely challenging. In this paper, we present lessons learned from the Catalyst project, which aimed to develop new digital technologies in close collaboration with non-academic communities. Catalyst formed partnerships between community members and academics, jointly agreed on a research problem and jointly worked towards a solution. In this way, academics and community members became equal partners in an attempt to break down barriers between academia and its walls. The paper gives a frank account of challenges encountered along the way and gives hints as to how these might be addressed in the future. These challenges are categorized into: working in the community, research innovation, working across disciplines, and practicalities. These are illustrated, where appropriate, by reference to a range of communityuniversity research partnerships set up as part of the Catalyst project.
\end{abstract}

\section{Introduction}

A recent trend in Human-Computer Interaction (HCI) research is to take researchers away from the safety of their labs and ask them to carry out development embedded within a community. This so-called "research in the wild" (RIW) $[1,2,3]$ is seen as a

Jon Whittle

School of Computing and Communications, Lancaster University, InfoLab21, South Drive, Lancaster University, LA1 4AW, United Kingdom e-mail: j.n.whittle@lancaster.ac.uk 
paradigm shift in HCI research which has a long tradition of controlled experiments with participants who are brought into the lab for fixed periods of time. The move towards RIW is to overcome some limitations of lab-based HCI research, such as the inability to generalize results obtained from controlled laboratory settings to the noisy, uncertain and constantly changing contexts of the real world [4]. At the same time, RIW brings new challenges in carrying out real-world deployments of research prototypes: such prototypes need to be usable, reliable and robust over long periods of time and in evolving and challenging environments [4].

Although RIW may have specific challenges of its own - such as the need to respect participants' data privacy preferences, which may be significantly more challenging than in a lab environment - many of the challenges faced and, therefore, many of the methods used by RIW researchers are much more familiar. RIW often draws on action research [5], participatory design [6], co-operative inquiry [7] and methods of co-design [8]. These approaches address issues of participant engagement, ethics in real-world scenarios, and long-term sustainability of solutions by encouraging users to take ownership; these issues are not new or specific to RIW, although the focus on technical innovation may provide a different perspective. Indeed, anthropologists and sociologists have arguably been carrying out RIW for hundreds of years; for them, doing research in the "real world" is standard.

Attempts at RIW to date have been numerous (see [4] for good examples) but largely remain researcher-centric. That is, the researchers retain control - they define the research questions, the research methodology, and the research outcomes. The research team goes out "into the wild" but few, if any, decisions are made by participants in deciding what to study. This goes against many of the fundamental principles of methods such as co-production, where emphasis is placed on users taking ownership of a product to be developed as a way to encourage more active engagement with it.

In the Catalyst project $^{1}$, an initiative at Lancaster University, we have made a serious attempt to involve communities - charities, social enterprises, community groups and individuals - as equal partners in a range of research projects. Communities and academics jointly define the research questions to be studied and jointly imagine and build digital prototypes that in some way address social challenges embodied in those research questions. Over the last three years, Catalyst has carried out twelve such research projects. Each has produced a digital prototype which has been co-produced and then evaluated "in the wild". These projects have been quite diverse in topic area - ranging from technology for hard-to-reach groups such as the homeless and autistic adults, to issues of sustainability such as technology to promote renewable energy and data analytics to promote more local spending. Despite this diversity, each project has been built on the same principles of communityuniversity partnerships leading to an "in the wild" research prototype.

Whilst there have been a great many successes in the twelve Catalyst research projects, there have also been numerous challenges. This paper gives a frank account of some of the challenges we have faced; we offer them as food for thought for

\footnotetext{
${ }^{1} \mathrm{http}: / /$ www.catalystproject.org.uk
} 
others embarking into community-university technology-driven research projects. These challenges are structured into four different categories: those related to working in the community (i.e., outside of a University research lab); those related to how to ensure innovation in community-focused projects; issues of cross-disciplinarity, since these projects are cross-disciplinary by definition; and practicalities of making such projects work in reality. We raise a number of issues in these four categories illustrating them with specific instances from Catalyst projects. We also identify specific actions which helped to overcome some of the challenges that we faced.

\section{Terminology}

Before delving into the details of the Catalyst project, this section defines the terminology which we will use in the rest of the paper. Research projects that go "out of the lab" are common in a variety of disciplines, and a variety of methods have been used to facilitate such projects. Typically, each discipline comes with its own approach and terminology. Participatory design, for example, has strong roots in Scandinavia and has historically focused on bringing democratic principles to the design of new IT systems for the work place [9]. Co-design [8], on the other hand, comes from the discipline of design and implies that end-users do not merely "participate" but co-operatively design a product; hence, some would argue that codesign is inherently more participatory than participatory design [8]. A related term is co-production, an approach widely used for service design, which argues that those affected by a service are in the best position to (re-)design it [15]. In HCI, there is a long tradition of user-centered design [10]; again, the implication here is that users are consulted but do not necessarily make decisions. In addition to these approaches, there is also action research [13, 14], and, in particular, participatory action research (PAR) $[11,12]$, which involves an embedding of the research team into an environment where interventions are made in-situ in a series of iterative loops. PAR's central concept is that power is transferred from the researcher to the participants as a means of empowerment. Hence, in PAR, the community makes decisions about the direction of a project. Hayes discusses the relationship between action research and methods typically used in HCI [5].

A more recent term, which has come out of the HCI community, is research in the wild. RIW is defined as a specific attempt to encourage HCI researchers to leave the comfort of their labs and deploy working systems in the real-world [4]. This has very real implications as technological prototypes in the real-world must be robust, reliable and usable. A controlled lab-based experiment with a prototype need not satisfy such high demands. With RIW, the researcher is not present. Hence, whereas RIW presents compelling advantages in that it potentially offers more data in more realistic situations, it can be difficult to achieve in practice because researchers must go to the effort of developing industry-quality software for a fledgling idea that may ultimately not be worth it. 
In a sense, all participatory methods are "in the wild" - they inherently involve the researchers leaving the lab and engaging with end-users on the end-users' "home turf". However, not all RIW is participatory: a prototype could be designed exclusively by researchers but then deployed in a real-world situation without any input from end users at all.

In reality, it is difficult to draw clear boundaries between these different terms. Definitions presented in the literature can be at odds with each other, and researchers' perceptions about what is meant by these terms also differs. In addition, the very nature of participation means that approaches have to be adapted in-situ: participatory research projects typically involve a diverse set of people with different skills, opinions and backgrounds, and so whatever method is applied needs to be highly adaptive to an ever-changing context.

In this paper, we prefer not to use the term RIW at all. This is because the very phrase conjures up negative connotations. It implies that anything outside the lab that is, real-world situations - are "wild". And this is too easily interpreted as saying that the people, who are typically end-users or stakeholders of the research, are wild as well. This is not the kind of impression that a research project which cares about its participants ought to convey.

This negative connotation was starkly illustrated to the authors of this paper during a seminar a few years ago. A well-known speaker had been invited to Lancaster University to speak on issues of global sustainability and climate change. As this topic was of key interest to many local inhabitants of Lancaster, invitations had been sent out to the local community, and many local community groups had come to listen. After the talk, a discussion ensued about the value of community-University research. During this discussion, one academic commented that a grant had recently been acquired from a fund which aimed to support "research in the wild", and the academic went on to explain what was meant by this team. Predictably, the reaction of the local community was one of shock, mixed with a sense of amusement. Behind the humour, though, it had become clear that the very term "research in the wild" worked against the principles that RIW was aiming to follow.

This paper will henceforth, therefore, not use the term RIW. Instead, our focus is on what we call community-University research partnerships. Whilst this term is also not without its problems, we argue that the word "partnership" adequately captures the notion that, as in Catalyst, academics and non-academics jointly make decisions about the research project. All Catalyst projects were intended to follow the principles laid out below:

- A team made up of academics from multiple disciplines and non-academics (charities, community groups, social enterprises, and/or businesses) jointly decided what problem to address and jointly decided on the research questions to be investigated.

- The team jointly devised a "solution" in terms of a digital prototype, which was intended to address a social challenge in some small way. This prototype was jointly evaluated by the team in a real-world situation with real users.

- The team jointly made decisions about the future of the research project, i.e., whether it had a future, and, if so, what form that future should take. 
Hence, our notion of community-University partnership is that of co-production applied to technology prototypes with joint decision making at all points of the process. Whilst, in practice, some of the Catalyst projects followed these principles more than others, all projects made a serious attempt along these lines.

\section{The Catalyst Project}

For context, we briefly describe the Catalyst project. Catalyst (Citizens Transforming Society: Tools for Change) is a cross-disciplinary research project on digital social innovation where the research agenda is jointly set and carried out by academics and non-academics. Although Catalyst is first and foremost a research project, its goal was to have direct impact on communities through the research. Therefore, each Catalyst project was required to deliver academic publications but also a working digital prototype addressing a particular social challenge and a plan for disseminating and sustaining this prototype within the communities over the long term.

Catalyst sets up partnerships where academics and non-academics have equal status in defining and carrying out the research agenda. The guidance given to projects was that neither the academic nor non-academic deliverables should dominate at the expense of the other. All activity in Catalyst was expected to contribute to two broad research themes:

- What is the role of digital technology in addressing important societal challenges?

- What is the vision of next-generation technologies designed explicitly to address these societal challenges?

Catalyst is organised as a series of short-term research intensive cross-disciplinary sub-projects that each develops new digital technologies to address a social need. There are two types of project in Catalyst:

- Research Sprints last 6-9 months and must contribute to one of the Catalyst research themes. Each sprint is a "co-laboratory" in which academics and nonacademics immerse themselves in each others activities. Each sprint receives a grant to support the research as well as three (later, four) full-time research associates, each from a different discipline (computer science, sociology, management, design).

- Launchpads are smaller in size and are more speculative. Launchpads work as a pilot for ideas for future sprints or allow promising ideas that come out of a sprint to be continued. The duration of launchpads can vary but is typically between 4-9 months.

To reflect upon the ways of working, we applied PROTEE [16, 17], a management process designed to ensure that projects learn from failure as well as success. PROTEE involves several 3-hour dialogues with sprint and launchpad project teams to glean insights to support innovation, project management and cross-disciplinarity. 
Selection of sprints and launchpads is via an application process, mediated by procedures to match-make academics and non-academics. All projects must satisfy the Catalyst criteria: (i) the project must be a genuine partnership between a specific community group(s) and a group of academics - decision-making about the direction of the research is carried out equally; (ii) the project must address an important social challenge; (ii) the project must involve academics from multiple disciplines; (iii) the project must result in a digital innovation which addresses a real social need.

Over the last three years, Catalyst has:

- Carried out 12 community-University research projects

- Created a network of over 90 "\#catalystas" from various Universities and community organisations

- Successfully obtained or contributed to over $£ 900 \mathrm{~K}$ in follow-on funding for Catalyst research projects

- Been directly involved in, and made significant contributions to 23 public events outside of Lancaster University. Examples include Manchester Science Festival, the NHS Think-Tech Event, and Fueling Manchester.

- Published over 20 academic or non-academic publications

- Won the Telling Tales of Engagement award from the Engineering and Physical Sciences Research Council ${ }^{2}$ )

- Produced 13 videos, designed to bring research results to the wider community, all available on YouTube ${ }^{3}$.

- Given over 20 invited presentations on Catalyst, including invited seminars at UC Berkeley, the University of São Paulo and the University of Cambridge.

- Facilitated thousands of conversations between members of the University and members of local, national and international communities.

Catalyst projects have covered a diverse range of topics including: digital services for the homeless, a digital anxiety management tool for people with autism, a mobile trading tracking application aimed at supporting local trading practices, a tool for sharing biometric data across social networks aimed at supporting local athletes in improving performance, and tools that encourage energy users to reflect on the supply side of energy management so that society can be resilient in the face of inevitable energy shortages yet to come.

All these projects ${ }^{4}$ share the common themes of: (1) citizen-led innovation through equal partnerships between the University and its community; (2) digital innovations addressing real problems with real people; (3) a commitment to sustaining the partnerships over the longer term by providing assistance with follow-on funding and training in entrepreneurship.

\footnotetext{
2 www.epsrc.ac.uk

${ }^{3}$ https://www.youtube.com/channel/UCZYEeI1BZst8BDQ7cqnwKfQ

${ }^{4}$ For more details on all projects see http://www.catalystproject.org.uk.
} 


\subsection{Methods}

The twelve Catalyst projects have applied a variety of methods to ensure equal participation by academics and non-academics. Taken individually, none of these is new; it is in the integration of methods where Catalyst has innovated. For example, each of the sprints applied a project management framework which we call Speedplay [41]. Speedplay is a response to the fact that developing software prototypes to address social challenges requires new methods.

\subsubsection{Speedplay}

The value of software in promoting social change is now well recognized. In recent years, there have been attempts to boost such efforts by using rapid prototyping to quickly develop applications for a social context. One such effort is the rise of hackerspaces or hackathons, which are informal gatherings of software developers and representatives of community groups. These groups come together with the aim of developing software applications to address a social problem in a very short space of time (e.g., 24 hours or a weekend). Kera [19] followed and participated in a number of hackerspaces and found that they foster knowledge production and sharing between those involved, reinforcing a sense of community.

Despite these tangible benefits, in many instances prototypes from hackathons do not have a life much beyond the initial event. Although many hackathons aim to address a particular social issue, developers' understanding of the issue is usually obtained informally, through dialogue with social representatives present at the hackathon. This ignores formal methodologies from social science that are aimed specifically at gaining a deeper understanding of social contexts.

The integration of principles from user-centred design (UCD) with software engineering has been explored as a possible method to strengthen collaboration between users and practitioners, especially in agile development [23]. Like agile development, UCD has a core set of principles established in the 1980s [20]. Sharp et al. contend that UCD and the customer collaboration seen in eXtreme Programming (XP) already share the aim of "involv[ing] users effectively in software design" [21]. Indeed, they state that the integration of UCD techniques may be useful and welcomed by the software community. This sentiment is echoed by Fox et al. who observed the successful practice of varying degrees of UCD applied to agile development in the software industry [22].

As previously noted, Catalyst's main focus is social change. Here, software and digital artifacts are viewed as vehicles for social change, rather than end products or solutions to problems. It quickly became apparent in the early stages of Catalyst that existing methods from social and computer sciences were not adequate for the kind of social innovation that Catalyst aims for. On the one hand, whereas agile development methods are good at quickly prototyping potential digital solutions, they do rely on having a "customer" who gives feedback on current prototype iterations and decides which features to implement next. This remains true even when UCD 
is incorporated as in the approaches above. However, with the kind of democratic projects that Catalyst deals with, there is no single customer who can decide which features should be implemented. Rather, there needs to be a collaborative process of obtaining consensus around which problem to tackle and what a solution should look like. This, of course, is where participatory methods come into their own. However, participatory methods can often be lengthy endeavours taking many months to complete. This length of engagement was not possible given the short term nature of the Catalyst sprints.

The solution to this dilemma - that is, the Speedplay framework - is to combine agile, iterative prototyping with participatory action research in a way that gives sufficient time for cooperative engagement on a problem space (but not open-ended time), encourages co-design of potential solutions, and develops a final solution through agile, iterative prototyping. Added to this, Speedplay incorporates a streamlined version of the PRINCE2 management methodology [24] to ensure that the projects remain output-driven and consideration of the longer term sustainability of the projects is built in to the project from the beginning. We argue that, taken in isolation, none of these individual approaches (i.e., participatory action research, PRINCE2, agile methods) are suited to a software development context that aims to deliver: a) working digital prototypes with social impact, b) within a short time frame and c) in partnership with a range of stakeholders that includes community groups.

The Speedplay process model in Figure 1 shows each step of Speedplay flowing into the next. The process is paced through the delivery of tangible outputs or prototypes at each step. The prototypes may consist of both hardware and software and evolve from very early paper sketches to working prototypes. This output-driven, disciplined [25] approach is inspired by PRINCE2 but is a lightweight approach in that Speedplay produces minimal project management documentation, usually limited to monthly highlight reports. The steps in Figure 1 are of similar duration but of different 'pace' where the pace is relative to the time between each prototype version release. This is represented by the narrowing of the spiral from step 1 (slowest, a 10-12 week cycle) at the bottom, to step 3 (fastest, 2-3 week cycles) at the top.

Each step is characterized by a specific theoretic approach: the Prepare step is grounded in action research principles and deploys qualitative research methods for initial user requirement capture. Key for ramping up the pace of this first step is the focal point, an event usually scheduled within the first 10 weeks of the project requiring the team to collaboratively produce a tangible output for an external audience. The Design step embeds action research and participatory design principles into the design process and aims to visualize and design systems that can address user needs. This helps with the refinement of the requirements captured during step 1. The Build step adopts a classical agile approach with short development cycles; it further refines the user requirements and concludes with the release of a stable technology prototype. Stakeholders and end-users are involved at every step of the process, particularly in the Sustain step where wider partnerships are sought to support long-term development and deployments of the prototypes. The refinement of the user requirements is represented by the tapering of the spiral in the Figure 1. 
Figure 1 also highlights the differences between Speedplay and other iterative models such as action research, user-centred design, and spiral models in software engineering [26]. User-centred design (leftmost in Figure 1) supports iterative development through design, development, evaluation and analysis cycles [5] but users are not necessarily equal partners in the design process. Action research (centre in Figure 1 brings an incremental transformation of social practices through the continuous iterations of three phases: plan, act and reflect. Action research, like Speedplay, is incremental and works through iterations of planning, action and reflection. However, Speedplay allows specific methods and techniques drawn from both participatory design and action research to be adopted in parallel, separately or in combination depending on the context. The Speedplay model shares a similarity with Boehm's spiral model (rightmost in Figure 1) in that it is iterative; however, Boehm's is meant for large-scale projects whereas Speedplay emerged from smallscale projects. In addition, Boehm's spiral model is risk-driven, whereas Speedplay helps to pace uncertainties. In other words, Speedplay has an opportunistic approach to risk; in Speedplay, risks are treated as an uncertainty that has the potential to be harnessed, mitigated or discarded.

Further detail about Speedplay can be found in [41].

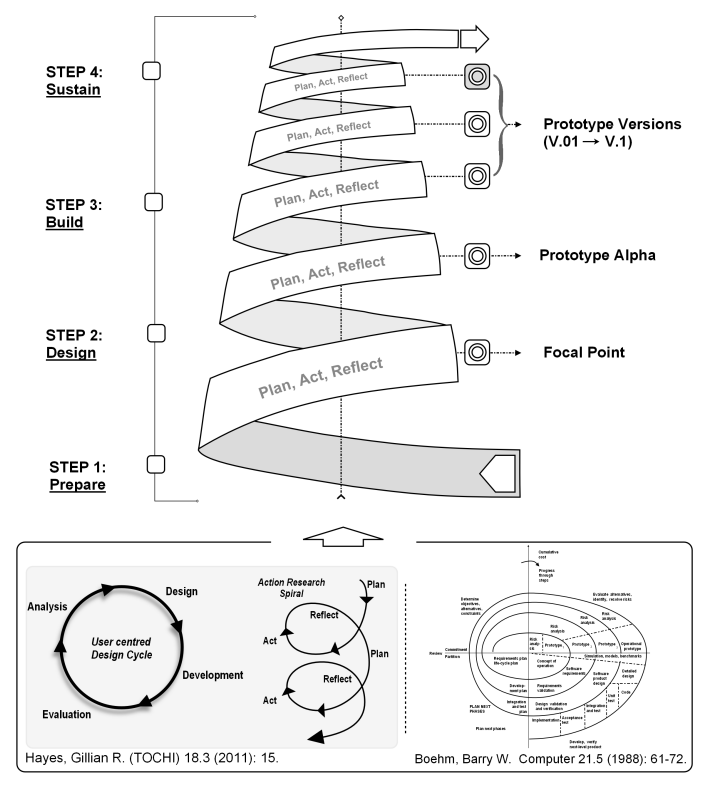

Fig. 1 The Speedplay Framework. 


\subsubsection{Other Methods}

Only the sprints in Catalyst applied Speedplay. This was because the sprints came with a team of researchers, whereas the launchpads were simply given financial resources to staff the project in any way that was appropriate. As a result, there is a greater diversity in the methods applied in the launchpads.

In the launchpads, existing participatory practices were widely employed - see $[6,27,28]$ for examples, many of which were followed. These practices were also applied within Speedplay; usually, particular practices were associated with a particular step from Figure 1. The key point to note is the flexibility required within the Catalyst projects: no single method was applied blindly; rather, a suite of methods were applied as circumstances demanded, which allowed projects to be adaptable to change.

Stakeholder meetings are formal meetings between the stakeholders of the project. In Catalyst, stakeholders typically include academic staff from multiple disciplines, representatives of community organizations or local authorities, and/or individuals who are the intended users of the technology to be developed. Stakeholder meetings are where progress is reviewed and decisions about the projects future direction are taken.

Co-Design workshops are events which bring stakeholders together to jointly imagine, build and develop a product [8]. In Catalyst's case, the product is a digital prototype. Co-design workshops are usually run democratically and give all stakeholders a chance to have input into what problem the group is trying to solve as well as the design of the solution. Co-design workshops can be used at any stage of development, from initial idea generation to solution development.

Co-Implementation is a special case of co-design where stakeholders jointly code the digital solution using an appropriate programming language. We distinguish co-implementation because of its digital nature, and hence, particular relevance to Catalyst. Co-implementation is a difficult activity to carry out because most stakeholders will not know how to code. It may need to be preceded therefore by up-skilling (see below).

Prototypes have been used in two ways within Catalyst. Firstly, they were used to explore a problem space in collaboration with stakeholders. As an example, in one project, the team wanted to build a relationship with residents of a remote Scottish island, who were potential users. To do this, rather than develop the final product immediately, the academics developed a digital Christmas tree and presented it as a gift to the residents. This is a form of technology-mediated co-design in which co-created prototypes are seen as a way to share knowledge rather than as an endproduct in themselves. Secondly, Catalyst has used prototypes as a way to gather requirements on the eventual product. As well as using traditional rapid prototyping techniques [29], where the prototype is an early version of the final product, Catalyst developed prototypes which may look very different from the final product but present alternative ideas in a way where concrete feedback can be elicited.

User trials, where users try out prototypes for extended periods of time, are, of course, important in evaluating the products produced in any participatory design 
process. In Catalyst, user trials were used in two ways: either with a narrow group of users selected from the project team, or a much wider group more representative of eventual users.

Training is important in Catalyst projects, and we consider this to be a participatory design practice because training allows users to better understand the designers' world, and vice versa. Catalyst used training in two ways: either to train academics in the domain of study, or to train stakeholders in research principles. An example of the former is where researchers needed training in issues of homelessness because they were to be working with homeless people. The latter tends to be more about communicating what research is all about (e.g., publishing conventions, setting research goals, importance of originality) rather than training in any specific method. Both types of training serve to build understanding across the team.

Side benefits refers to cases where a project undertook an activity off the main line of the project. For example, when working with a homeless charity, the project team built a new website for the charity. Since the website in itself was not a research project, it was not on the main line to developing the final product; however, it showed willingness from the academic team and therefore helped to build the relationship. Many of the Catalyst projects included this kind of side benefit. It is especially important in a partnership research project because the non-academic organization must accept that benefits from the digital prototype may only be realized in the longer term. These more immediate side benefits, therefore, mean that the project is less one-sided.

Up-skilling workshops are events where one group of stakeholders teaches the others a practical, hands-on skill such as computer programming, chemistry, or smartphone use. These workshops may develop skills that directly lead towards the final product, or they may be more about trust building. They also typically lead to side benefits as, for example, homeless people learn a new skill which they can write about on their CV and improve their employment chances.

Citizen science is a method for harnessing the collective power of a large population to carry out science [30]. It is more commonly thought of as using a crowd to collect data, e.g., bird sighting. Here, we use the term for any practice that crowdsourced opinion, design ideas, or design solutions. For example, one project on community film making built a crowdsourcing application for collecting short video pieces from the public as a way to build community cohesion.

Ethnographic methods includes any observational technique for studying users and understanding their context.

Focus groups are well-understood and were used frequently within Catalyst. Similarly, user interviews.

By digital ethnography, we refer to online observational methods. For example, one project studied problems experienced by adults with autism by observing an online community forum. 


\section{Challenges}

In this section, we unpick some of the major challenges we faced in applying the Catalyst sprint and launchpad model to community-University partnership research projects. We draw on specific examples where appropriate.

\subsection{Working in the Community}

At its inception, Catalyst articulated a strong principle of joint decision making in partnership projects. That is, projects were told to avoid a model of researchers as the drivers of the project. This principle was put in place for two reasons. Firstly, community groups were investing precious time in working with the university. Catalyst took their involvement seriously and wanted to avoid researchers "parachuting" in and then leaving nine months later when the funding ran out. Secondly, it was argued that community ownership of the research outputs was critical for longer term sustainability of the outputs and of the partnerships themselves. There was little point in researchers developing a digital solution if the community partners were not invested in its success and were prepared to take ownership of it in the longer term.

As working in partnership with communities was a major element of Catalyst, we reflect in this section on some of the major challenges we faced.

\subsubsection{Shared Values}

The vision for Catalyst was for truly democratic community-University partnerships. In practice, of course, the extent to which each Catalyst project achieved this democracy varied. All projects took a participatory approach to understanding the problem and designing a solution. However, the extent of participation differed across projects - cf. [31]. In addition, whilst the principle of democratic decision making is admirable in the abstract, in practice it can be difficult to achieve. Each project typically involved a wide range of stakeholders, each with their own desires and needs. These needs did not necessarily match, nor did each stakeholder necessarily understand the needs of the other stakeholders. Assumptions were rife and, inevitably, tensions surfaced from time to time when it became clear to one stakeholder that their desires did not match the others.

Table 1 summarizes some typical "needs" of a variety of stakeholders in various Catalyst projects. For example, academics have a primary need to publish, whereas community groups at least partially need to demonstrate some short-term tangible benefit which they can use to satisfy their funders. Similarly, local authorities need to address internal government priorities as well as to provide a benefit to those who use their services. Table 1 is intended to be illustrative only and in no way completely captures the complex set of needs of a wide range of different stake- 
holders. Indeed, in all cases, stakeholders typically had an underlying personal need to "make a difference". One should not ignore the fact, however, that stakeholders have pressures on them from their institutions and/or funders which mean that they have to produce certain kinds of outputs. And these outputs may differ according to the stakeholder.

We discovered early on that it is difficult, if not impossible, to fully articulate the needs of all stakeholders at the beginning of a project. Whilst all projects had a written, and signed, contract describing what the project set out to achieve, the needs were not explicit in the contract. The reasons for this are twofold. Firstly, not all stakeholders knew their needs at the beginning of a project, or were not upfront about them. Secondly,the participatory nature of the projects meant that the outputs changed frequently mid-stream. Early work in the Catalyst sprints realized that "need" or "desire" of stakeholders was not the right level of discourse. Rather, a much more constructive approach was to talk about "values". Whereas stakeholders might differ wildly in their needs, they often had a core set of values shared by all. Where values were not shared, this inevitably led to members of the team disengaging or even leaving the project.

\begin{tabular}{|l|l|}
\hline Stakeholder type & Example needs \\
\hline Catalyst Principal Investigator & $\begin{array}{l}\text { Conference and Journal Publications } \\
\text { Non-academic impact }\end{array}$ \\
\hline Academic Staff & Conference and Journal Publications \\
\hline Post-doctoral researcher & $\begin{array}{l}\text { Conference and Journal Publications } \\
\text { Career development }\end{array}$ \\
\hline Community group & $\begin{array}{l}\text { Positive impact on community members (e.g., } \\
\text { upskilling, empowerment) } \\
\text { Financial assistance } \\
\text { Short-term benefits (e.g., new website) }\end{array}$ \\
\hline Social enterprise & Solution with a viable business model \\
\hline Local authority & $\begin{array}{l}\text { Adherence to government priorities and objec- } \\
\text { tives }\end{array}$ \\
\hline $\begin{array}{l}\text { Those served by a community group or local au- } \\
\text { thority }\end{array}$ & Impact on personal situation \\
\hline
\end{tabular}

Table 1 Examples "Needs" of Different Stakeholders.

The truth is that, for most Catalyst projects, no stakeholder group's needs dominated, and, it could be argued, that a different kind of project would better have served individual needs. For example, if the only concern is for academic publications, a more effective approach would have been to carry out a series of lab-based experiments on new digital prototypes and reduce the participatory aspects. Similarly, more immediate impact on community groups could have been provided by giving a small amount of money for a near-term, non-research objective, such as a new website. The benefit of Catalyst projects, therefore, lies not in servicing any one stakeholder group's needs, but in forming relationships that potentially survive in the longer term and inspire and empower the participants. This is exactly where a set of agreed values becomes crucial. Although stakeholders may have differed in 
terms of how they were to be ultimately evaluated (e.g., on publications versus level of service provided), values, such as the desire to improve society through the use of digital technology, were shared in most cases.

As a concrete recommendation for future partnership projects, the Catalyst experience recommends that project stakeholders explicitly capture their shared values at the beginning of a project and, moreover, that these values are revisited from time to time during the project, especially when key decisions need to be made. Although this was sometimes done within Catalyst, the application of this recommendation was patchy. A number of frameworks for discussing values in a simple and straightforward way are available. One example is the Common Cause Handbook, which advocates a focus on intrinsic values over extrinsic "needs" [32]. There is also research in values-based design which is relevant here (e.g., [33]).

\subsubsection{Management}

Another important challenge for community-University partnerships is who makes key decisions. Given that the Catalyst projects were run on democratic principles, and given that the needs of each stakeholder were so different, it is clearly a difficult task to make decisions in a way that keeps all stakeholders engaged. Although each Catalyst project had a designated project leader - sometimes an academic, sometimes from a community - the line management structure was non-traditional. In the sprints, for example, there were 3-4 post-doctoral researchers working full-time on a sprint. The project manager was typically only allocated $10-20 \%$ of their time due to other commitments. Both academics and community activists have to juggle many balls; this meant that many project managers did not effectively keep up to date with the work of the researchers, who were often left to manage themselves. This in turn made it difficult for project managers to make key decisions, because they did not necessarily have the backing or knowledge of the researchers.

In many cases, key decision points were where the mismatch in needs resurfaced. As an interesting example, we refer to the second Catalyst sprint, a project called Access ASD, which aimed to use digital technology as a means to support autistic adults in their daily lives.

In the Access ASD project, a partnership involving a multidisciplinary team of academics, care-service managers from a local authority, mental-health therapists and practitioners from national Autism charities came together for nine months. The initial brief was intentionally wide: investigate technology applied to social anxiety experienced by adults diagnosed with High Functioning Autism/Asperger Syndrome (HFA/A). In the end, a technical prototype called Clasp emerged from a deep insight into how anxiety is experienced by HFA/A adults. Clasp [34] is a novel tactile anxiety management, communication and peer support tool. Clasp connects a tactile anxiety coping device to a smartphone, which records and communicates anxiety levels for self-feedback and reflection. The data may be shared for real time online social network support, or aggregated over time to allow users to identify patterns or situations in which they feel most anxious. This can then lead to be- 
havioural interventions, either applied personally or suggested by clinicians. Clasp was prototyped with a Bluetooth connected stress ball, Android smartphone and the Diaspora social network — see Figure 2.

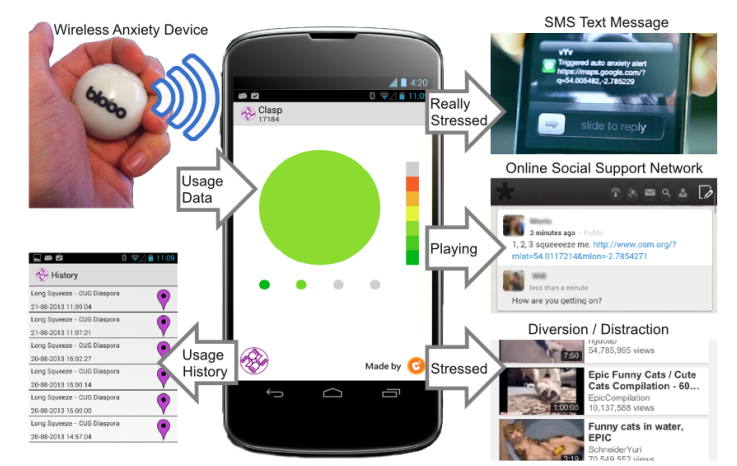

Fig. 2 Clasp: A Digital Tactile Anxiety Management Device Supporting Self-Reflection.

Access ASD, as other Catalyst sprints, was managed using the Speedplay framework. One aspect of Speedplay is that there are focal points during the co-design process, where important potential ideas are considered and then selected. These focal points are crucial decision-making events: as with any co-design project, the opening up of ideas eventually has to be anchored into a specific project that is to be produced. In Access ASD, a major focal point arose after a week long retreat by a subset of the research team. Before the focal point, a number of competing ideas had been suggested. After the focal point, a decision was made to pursue the ideas that would eventually become Clasp.

It was just after this focal point that tensions arose as to whether Clasp really was the best choice as the digital output of the Access ASD project. It emerged that some of the project stakeholders had different ideas in mind as to what should be developed, and that these ideas, whilst claimed to have been in the mix since the beginning of the project, had not necessarily been articulated before. In essence, the choice was between Clasp, which was considered by some in the research team to be an innovative and highly novel application, and a more traditional social network that would both serve as an information portal where autistic adults could go for help, but would also serve as a way to identify autistic adults not currently known to the local authority. The thinking was that an information portal would "draw in" autistic adults, who would then have the opportunity to use the local authority support services. This need to identify as yet unknown participants was seen as important by the local authority because of an internal mandate to improve access to their services.

These two very different visions resulted in tensions that were never fully resolved. The decision was made by the post-doctoral researchers to go with Clasp. This was the preferred choice of the so-called "core user group", a small group of autistic adults that had been involved in the co-design process. It was not, however, 
the preferred choice of the local authority. The problem surfaced tensions between the core user group, the post-doctoral researchers, the local authority and the academics on the project. Curiously, the local authority, whose role ostensibly was to serve autistic adults such as those in the core user group, disagreed with the core user group as to the direction of the project. These disagreements were serious enough that personnel left the project soon after this: a senior academic left and the local authority representative considering leaving, before eventually deciding to stay and putting his support behind the Clasp development.

This example illustrates some of the realities of co-design and participatory projects. In the participatory design literature, the word "democracy" is prominent. There is much talk of the intangible benefits to those who participate: they feel listened to and empowered. However, this is to mask the realities of what happens when hard choices have to be made, choices that, by definition, will not satisfy everyone.

This example also points to one of the major difficulties which projects like Catalyst face: the lack of managerial expertise. Management is difficult at the best of times. Managing cross-disciplinary projects is more challenging still. Imagine then the complexity of managing a multidisciplinary project with community participation at multiple levels - core user group, local authority, other related stakeholders. There are very few managers who are equipped to deal with such complexity. One recommendation from the Catalyst experience then is as follows: given the recent trend towards cross-disciplinary research, as promoted by research funders across the world in an effort to tackle the so-called "wicked" problems that need expertise from multiple disciplines, there needs to be greater consideration given to training managers and future leaders of such projects. It is not enough to set projects up and then leave them to it.

\subsubsection{Responsible Innovation}

Ethics approval by University committees is standard procedure in research projects. However, our experience with community-University partnerships has raised some particular issues related to responsible innovation that are not typically considered by ethics committees.

The first of these relates to the investment of time from community groups and the expected return on that investment. Catalyst took pains to make it clear from the beginning that the partnership projects were research projects and hence could not offer any immediate tangible benefits to community groups getting involved. In order to clearly manage expectations, discussions took place as to exactly what research means. It was clearly explained that Catalyst projects would only result in benefits in the longer term, if at all, and that the benefits might be to a broader group rather than directly to the community group involved in the project. To their credit, all the community groups responded well to this. Indeed, it appears that community organisations are much more willing than, say, businesses to take a leap of faith into 
the unknown if there are potentially wide-ranging societal benefits down the line somewhere.

Catalyst considered, however, that simply managing expectations in this way was not a sufficiently considerate way of treating community groups. To further support the community groups that got involved in the research, two actions were put in place. The first was a decision that community groups could, and should, be paid for their time. This is not necessarily a trivial decision to take. UK Research Councils fund research and this typically means that staff costs are expected to be in terms of academic or research staff time. Indeed, the original funding bid for Catalyst did not include staff costs for community organisations; rather, a budget was included to pay participant expenses, but not a way to directly pay staff time on the community side. Within the first few weeks of Catalyst, however, it became clear that this was not presenting the right message: Catalyst was technically funded to the tune of $£ 1.9 \mathrm{M}$ (although around half of this was immediately lost in University overheads) and so to offer nothing to community groups would be patently one-sided. Catalyst got around this problem by paying community staff as researchers: these projects were research projects, after all, so community staff working on them could be considered researchers even if they did not have the $\mathrm{PhD}$ to show for it.

The second decision that Catalyst took was to consider the sustainability of Catalyst projects from the beginning. Procedures were put in place from day one of each project that would support the projects in having a lifetime beyond the Catalyst funding. A dedicated sustainability consultant was hired to provide support to all projects. More than this, though, the researchers took it upon themselves to embed a consideration for sustainability into the projects from the beginning; indeed, this became a core part of the Speedplay process used in the sprints. In terms of how this was achieved in practice, there was no magic formula. Rather, the sustainability issue was always at the forefront of any conversation about the future of the project. Links within and outside the project team that could support sustainability were actively fostered. This, of course, takes a substantial amount of time, and comes back to the issues of "needs" outlined in Section 4.1.1: it was not necessarily in the interests of the researchers to pursue a sustainability agenda because it meant taking time away from writing publications; however, the researchers considered sustainability to be a top priority and put their personal resource into it accordingly.

In large part, the sustainability efforts in Catalyst have been successful. Most projects have a life beyond the original Catalyst funding. The exact nature of this life differs in each case. The digital prototype from the first sprint, \#Pat, became the inspiration and a core work-package for a successful $£ 300 \mathrm{~K}$ Big Lottery Fund bid, put together by a consortium of charities in the NW of England, and aiming to use the prototype as a front-end to a case worker database. Although this followon project is now funded and operating, it remains to be seen to what extent the \#Pat prototype will remain part of it. The Big Lottery bid included more "mundane" plans in addition to those inspired by \#Pat, and there is a danger that, over time, the \#Pat element will get lost. This illustrates the difficulty of sustaining research projects, even when there is subsequent funding: to maintain the \#Pat ideas upper- 
most, constant nudging is required from the original project team, but this becomes increasingly difficult over time as the research team has moved on.

Despite the successes in sustainability in Catalyst - which, in addition to the Big Lottery grant mentioned above, includes two further Research Council grants totalling $£ 550 \mathrm{~K}$ - this success has not come without difficulties. If we were to design Catalyst from scratch again, the single biggest thing we would change is the inclusion of business expertise into projects. Although there was a business specialist serving on the Catalyst advisory group, Catalyst projects did not have their own dedicated business expertise to draw on. This usually became a problem because the teams reached a point where they would like to explore commercial opportunities, but lacked the knowledge, expertise or time to do so. Access ASD was a good example of this. Towards the end of the project, team discussions focused on perhaps creating a social enterprise to take Clasp further. However, no-one on the team had any experience of creating a social enterprise. Nor did anyone have the time to commit to such a thing: everyone already had "day jobs". In the end, a decision was made to go for additional research funding (which was successful) to collect more evidence of the effectiveness of Clasp, and to explore commercial opportunities further down the line.

Another issue related to responsible innovation relates to the well-being of the postdoctoral researchers. In Catalyst, the researchers switched projects every nine months. This led to problems due to the social mandate of Catalyst to work with under-represented and marginalized groups. In the first two years of Catalyst, the researchers first worked with homeless people and then with autistic adults, having had no experience of working with such groups in the past. Research leaders should not underestimate the stresses that can be put on the research team when they go into situations such as these. Although Catalyst endeavoured to provide training in the relevant issues at the start of each sprint, this training was necessarily light-touch and could not prepare researchers for the emotional burdens that come with working with groups such as the homeless. Researchers were often asked to serve as proxy counsellors or got involved in personal problems of participants. This is a problem with all participatory research but was exacerbated in Catalyst because of the model of a series of quick sprints, which demanded that the researchers switch from one sensitive project to another.

The conclusion of Catalyst here is that ethics processes are set up to "do no harm" to participants, but they typically do not give much, if any, consideration to the well being of the researchers themselves. Our recommendation is that ethics committees take a good look at this issue, especially in HCI research where such considerations are perhaps less usual than in, say, health and medicine research.

This discussion plays into the broader context of responsible innovation [35]. There have been recent attempts to take a more holistic view of what responsible innovation means. For example, a European report looks at issues surrounding emerging technologies such as nanotechnology and synthetic biology and hopes to ensure that research in these areas is undertaken with consideration of potential negative side-effects [36]. In the UK, the Observatory for Responsible Innovation [37] provides resources for research that considers social conscience. The debates within 
this broader responsible innovation literature, however, are somewhat different than the ones considered in this section. Rather than concerning itself with general issues of the social responsibility of science, Catalyst has encountered very specific challenges related to well-being of community partners and researchers themselves when engaging in real-world research on social issues.

\subsection{Novelty in Community-University Partnership Projects}

One question about community-University research projects, and participatory projects more generally, is to what extent their outputs are genuinely novel. On the one hand, it can be argued that academic staff know how to innovate and therefore, these research projects will be innovative. On the other hand, the need to work with a community group, which may have more immediate needs, could act to counter more radical thinking. In this section, we discuss a number of issues related to the levels of novelty and innovation achieved in projects like Catalyst.

\subsubsection{Mundane versus Revolutionary Innovation}

The first issue is what Wilson and Blackwell call incremental versus radical innovation [38], or what has been elsewhere called mundane versus revolutionary innovation. It can be argued that cross-disciplinary research more readily leads to radical innovation because it encourages researchers to cross disciplinary boundaries and hence be exposed to whole new ways of thinking. On the other hand, crossdisciplinarity can lead to compromise between the disciplines as radical innovation in any given discipline is discouraged because of the need to fit in with the other disciplines.

This tension risks being exacerbated in community-university research projects, which are not only cross-disciplinary but are also involve community groups. On the one hand, communities should have a better understanding of "real" problems, and so the results of the research should be more useful. On the other hand, communities will naturally have an understanding of their own particular problems and may not necessarily understand the bigger picture, so research results may not be generalizable. In particular, it can be argued, community organisations are investing scarce resources - their staff time and energy — into a research project, and so will want to see some tangible benefit in the near term. This situation can be guarded against - as Catalyst has done - by carefully managing expectations, but when push comes to shove, it may be that community-University partnerships default to the more familiar.

An interesting example of this was in the first Catalyst sprint, a project called \#patchworks. \#Patchworks brought together a charity providing support services for the homeless with a group of academics from social, computing, environmental and health sciences. The team came up with a number of interesting ideas for digital 
prototypes that could, in some small way, assist either homeless people or those who provide support to the homeless.

In \#Patchworks, this meant choosing between two prototype suggestions: a handheld microbe detector and an RFID appointment printer (see Figure 3). Each object promised a different kind of future, and many strong opinions were held on the different values that each represented. The microbe detector was a device for measuring the state of living conditions of the homeless, envisaged as a low-cost version of more expensive commercial devices. The RFID appointment printer was a way for those without internet access to quickly and easily get personalised information on services by swiping a RFID-enable card or bracelet. The microbe detector would facilitate a political statement; it was a way of showing politicians and public services the unhealthy conditions that homeless people were sometimes expected to live in. The printer was a more obviously useful device: it was a way of providing internet access about important medical and service to appointments to homeless people who otherwise do not have access to such information.
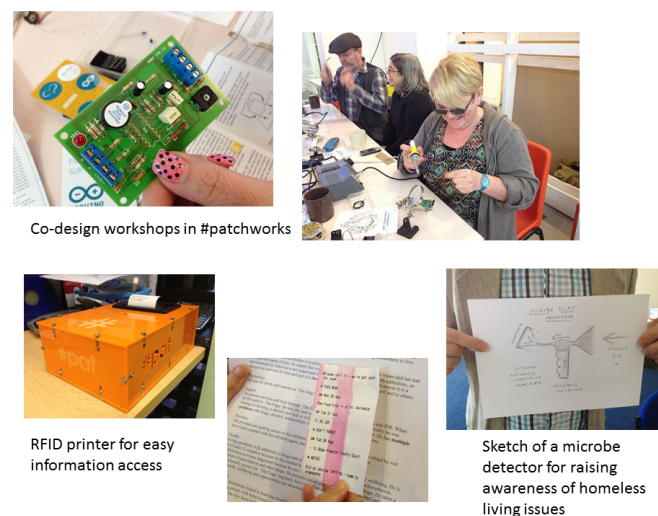

Fig. 3 Competing Prototype Ideas in the \#Patchworks Project.

These two potential prototypes embodied different aspirations. The microbe detector was more radical and more risky; it represented the political idea of a collective action but it also mobilized a fear of individuals being recognised as "trouble" by landlords and social services, of accommodation being closed down for renovation and its inhabitants being made homeless again. Nevertheless, the enthusiasm and empowerment around discussion of this object, the imagined future of being able to have a voice and be heard by those in authority, was plain to see and hear in the enthusiasm of participants.

The RFID printer, however, was seen as something much more readily put together; as a device it could be made and trialled easily with a small number of participants using low cost hacking and assembling methods. The main discourse around it was that it would help to organise the lives of chaotic people. Initially unspoken, but nevertheless recognised, was that this was imagined to make the lives 
of those involved in the workshops easier and so would have an immediate effect on the work of charity. Although this was the least radical option, it was far more tangible and closest to the everyday reality of homelessness.

In terms of deciding which of these two prototypes to pursue, there were different risks associated with each prototype, and different voices supporting those risks, with different kinds of power associated with them. While representatives of the charity and the University endorsed the RFID printer, the postdoctoral researchers and service users expressed enthusiasm for the microbe detector, suggesting that it gave marginalized people a new voice through collective action and a kind of scientific evidence.

In the end, it was decided to go with the printer, for the reasons that it provided a more realistic and tangible short-term benefit. As the \#Patchworks project leader said, "It ticks all the boxes". It was suggested that the microbe detector could be pursued as a separate, new project. Enthusiasm for participation in \#Patchworks dropped off at this point as some volunteers and service users stopped attending workshops. The future that was being built through them was not / no longer the one that they most wanted. The seemingly less risky prototype, was not without its own risky consequences; like other mundane outcomes, its riskiness was disenchantment and disappointed expectations.

The example illustrates a natural trend towards the mundane, even if this trend was never explicitly acknowledged. It arises in a completely understandable way. Academics are trained to push boundaries, community groups are not. And in a community-University partnership, the natural inclination of academics to go beyond these boundaries is dumbed down because of the desire to help the communities and the people that form them.

Catalyst attempted to guard against these pressures in a number of ways. Catalyst projects were given informal mentors who could be consulted for advice on which was the best direction to take. The Catalyst Principal Investigator often acted in this capacity and, in some cases, pushed projects towards a more innovative path than otherwise might have been taken. There remains a question, of course, as to what is considered to be innovative, as different disciplines have different ideas about innovation. We discuss this particular consideration further in Section 4.3. In addition to the mentors, the Catalyst sprints made efforts to provide communities with more mundane side-benefits as part of the participatory process. For example, the researchers in \#patchworks managed to procure a new, free website for the homeless charity: this new website did not contribute to the overall research goals of the \#patchworks project, but it took the pressure off somewhat as it gave much more direct benefits to the community organisation thus freeing the community from worrying too much about whether participation was worth its time.

Overall, it appears that from a technological perspective, Catalyst has not been radically innovative. There is no new piece of hardware, no new programming language, or no new algorithm to come out of Catalyst. But then this was never the intention of Catalyst. Such innovation, although it may require inspiration from other disciplines, is grounded in a single discipline. Catalyst, on the other hand, was always more about the application of novel technologies and the innovation therefore 
comes from the application of technology in a new and interesting context. There is, however, a wide disparity across Catalyst projects as to the level of innovation of the final prototype products: compare, for example, the RFID printer from \#patchworks with Clasp, the digital anxiety tracking device from Access ASD. The latter is clearly more "innovative" if the technology alone is considered.

\subsubsection{Innovation in Process}

One realization that came early in Catalyst was that the innovation in Catalyst comes not only from technological outputs but also from the processes that are applied. This was particularly true in the sprints, which devised a whole new process, Speedplay, described earlier in Section 3.1.1.

Here, we briefly illustrate Speedplay on the third Catalyst sprint, OnSupply. OnSupply was a nine-month partnership with the Tiree Development Trust looking

at the challenges and opportunities posed by the time-varying availability of renewable energy supply and the role of technology in addressing such challenges and harnessing the opportunities. Tiree is a remote island off the coast of Scotland on the edge of energy supply and communication infrastructure. A few years ago, the Tiree community got together and acquired funds to install a community windturbine, "Tilley", which was erected in 2010. The OnSupply vision for Tiree, as a community, is to become an exemplar of a future sustainable and integrated energy ecosystem.

onSupply included an interdisciplinary team of academics (software and electronic engineering, $\mathrm{HCI}$, interaction design, and management), and freelance developers from Lancaster, Dundee, and Tiree. Every month, the researchers of the core Catalyst team in turns took the responsibility for organising research and development activities on Tiree according to their skills and the phase that the project was at. On the island the team lived together and engaged with project stakeholders and the community both in research and in social activities.

As a result, the project developed a suite of technologies that were created, produced, assembled, and developed in partnership with the community. Such technologies were never presented as 'solutions' to problems but as means to better understand the connection between the natural elements (sun, wind, water) and the energy that we use in everyday life. One of our participants who helped with the development of one of the prototypes - the Tiree Energy Pulse - defined it as "an interactive and visual way of seeing the energy and the weather and the relationship between the two so that you get [...] the feel of the wind versus how much energy is being produced". Five prototypes were developed over the course of the project (Table 2). These were showcased during the Tiree Agricultural Show in July 2014 (Figure 4).

The OnSupply project illustrates the principles of the Speedplay innovation management framework. As described earlier, Speedplay is a reflective process characterised by four distinct and iteratively overlapping phases: prepare, (co)design, build, and sustain. Crucially, Speedplay is not dogmatic about its methods, but 


\begin{tabular}{|l|l|l|}
\hline Prototype & Description & Reach at end of project \\
\hline Energy Pulse App & $\begin{array}{l}\text { renewable energy data forecasting system for re- } \\
\text { sponsive and responsible energy consumption }\end{array}$ & Households, workplace \\
\hline Energy Detectors & $\begin{array}{l}\text { renewable energy data discovery and measure- } \\
\text { ment devices }\end{array}$ & Children, school \\
\hline Energy Data Hub & $\begin{array}{l}\text { on-line data map for energy detectors data log-in } \\
\text { and open energy data access }\end{array}$ & Families, general public \\
\hline Datarium & $\begin{array}{l}\text { energy data display system for forensic environ- } \\
\text { mental science }\end{array}$ & School, public spaces \\
\hline SQRL & $\begin{array}{l}\text { energy-data radio-controlled system for automa- } \\
\text { tion of renewable energy consumption }\end{array}$ & Households, workplace \\
\hline
\end{tabular}

Table 2 Five OnSupply Digital Prototypes.

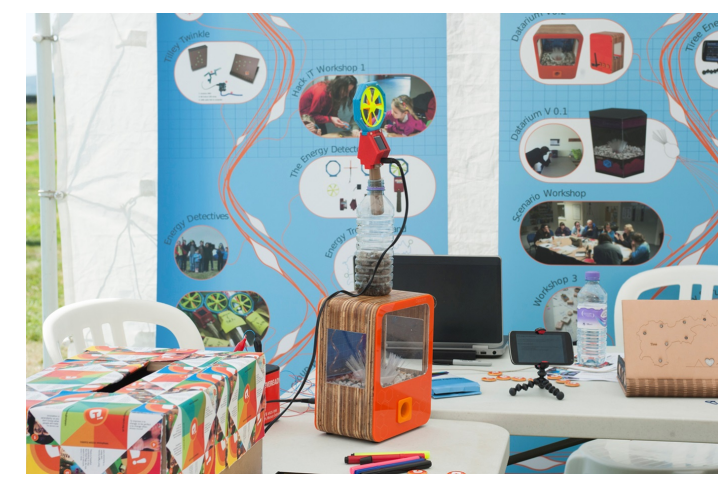

Fig. 4 Sample Prototype from the OnSupply project

applies whatever methods are appropriate for a given point in a given phase in a project. To hold everything together, Speedplay adheres closely to six core principles: 1) work in partnership with all stakeholders including end-users; 2) support team building by engaging in cross-cutting tasks; 3) promote individual selfdirection by matching individual skills with primary responsibilities; 4) be 'undisciplined' with methods; 5) be opportunistic with change, and 6) develop technology as part of the enquiry [41].

\subsection{Working Across Disciplines}

Community-University partnership projects are by definition cross-disciplinary. They tackle a particular social issue and a full understanding of a social issue can only be achieved by approaching the problem from different angles. \#Patchworks, for example, involved academics from health and medicine, computing and social science, as well as experts in providing services to the homeless, and, of course, homeless people themselves. Access ASD included academics from sociology and computing as well as experts on providing services to autistic people, and autistic 
people themselves. OnSupply included academics from computing and design as well as a wide range of representatives from a remote local community and from sustainability experts.

As anyone who has tried it knows, working across disciplines is difficult. There are the oft-cited terminological misunderstandings, but these are just the tip of the iceberg. Understanding each other turns out to be the easy part. It is relatively straightforward to get past the barrier of unknown terms. However, getting past unwritten assumptions and deeply held prejudices - which all disciplines have - is much harder. Academics from a particular discipline have been trained for decades in how that discipline works: how it thinks, which methods it applies, and what is the "right way" to do things. The academic system encourages academics to be protective of their discipline; academics, if they are not careful, will view their own discipline as superior to others, which clearly makes working across disciplines problematic.

In this section, we reflect on our own experiences of cross-disciplinarity from within Catalyst. However, rather than dwelling on the positives of cross-disciplinarity - which have been widely written about and promoted (cf., for example, [38, 39, 40]), we focus on the challenges of cross-disciplinary research. This is not to say that we disagree with cross-disciplinarity. Quite the contrary: we agree wholeheartedly with the argument that today's problems (such as climate change, deep social inequality, and global poverty) are too "wicked" for a single discipline to tackle alone. However, we do not wish to repeat oft-cited arguments in favour of crossdisciplinarity, and so, instead, take the contrary view, if only to balance the discourse a little. Below, we present, somewhat tongue in cheek, our top reasons not to get involved in cross-disciplinary research.

Before we do so, we give a quick disclaimer. Our comments here focus exclusively on the academic side of cross-disciplinary research. Catalyst actually involves two elements of working across disciplines: academics from different disciplines working together, and academics working with non-academic experts. Frankly, the former is much more problematic. In the latter case, people are driven much more by solving a problem and are less dogmatic about particular methods that should be used. That is not to say that there cannot be tensions between non-academic experts and their academic counterparts. We have certainly witnessed some tensions. However, we do not focus on them here as they have been largely covered in Section 4.1.

\subsubsection{Reasons NOT to do cross-disciplinary research}

It takes too long to unlearn disciplinary bias. Each discipline comes with its own (biased) set of methods, ways of working, philosophies, and idea of what constitutes an "output". Reconciling conflicting philosophies can be extremely challenging, if not impossible. An academic from a certain discipline will have been trained to think in a certain way since at least their doctoral, if not their undergraduate degree. It is almost impossible to overturn prejudices from these philosophies: even if an 
academic is open and willing to do so, the publication culture in his/her discipline may not allow it.

One example of this kind of clash of philosophies is that between computer science and critical theory in the social sciences. On the surface, a combination of critical theory and computer science could offer some fundamental advances in thinking in digital innovation. Computer science could be criticized, for example, for not always fully appreciating the ramifications of developing new technology: an obvious example is the development of social networks which offer unprecedented ways of allowing people to connect but come with consequences in terms of corporate control of people's private data. A critical approach, taken before a new technology is developed, could uncover some of the hidden assumptions of the technology and hence guard against some of the negative connotations of a new digital innovation.

In practice, however, such a combination is deeply problematic. The early Catalyst sprints tackled this head-on by integrating sociologists, taking somewhat a critical approach, into the software development teams. However, this simply did not work. Anything can be critiqued. And it is easier to critique than to offer solutions. What happened in some of the Catalyst projects is that computer scientists or designers would come up with ideas of systems to develop, which were then inevitably critiqued, perhaps on reasonable grounds. The social effect of this, however, is that the sociologists come across as consistently negative and overly critical; they are not offering their own solutions to the social challenge (or at least not technologically innovative ones) and become a barrier to progress. Their interest is ultimately not in digital innovation at all, but in a socio-theoretic understanding of the problem under consideration. This illustrates starkly how academics, through no fault of their own, are often unable to step outside their own disciplinary prejudices. In this example, a critical theorist needs to accept that not everything should always be criticized and find a way that critical theory can contribute to digital development without shutting it down. We will put our hand on our heart and say that Catalyst failed to do this.

We do not mean, of course, to lay the blame solely at the door of the critical theorist. The computer scientist and designer must also be willing to modify the way they work. Computer scientists and designers like to build things, and improve things by iterating on built artefacts. One could argue that they need sometimes to be more willing to step back and be self-critical about their own artefacts. But this is a debate that will continue beyond the confines of this paper: the benefits and drawbacks of just "doing it" and seeing what works are in conflict with those of taking a more deeply theoretical rather than experimental approach.

Time is relative across disciplines. Different disciplines work at different timescales. We have already commented, for example, how agile software development methodologies, created in response to a rapidly changing software industry, are all about speed, whereas many methods of social science take much longer. It can take years to properly carry out even a relatively straightforward interview-based study. Participants have to be recruited, then interviewed. Interviews are then transcribed, at which point begins the lengthy process of analysis and synthesis of interpretations of the data in the interviews. In contrast, the software industry moves at a lightning fast pace. Technology, whether you like it or not, changes very quickly. A computer 
scientist hoping to make impact on the world of technology simply cannot spend years analysing and understanding a problem; the technology will have moved on by then.

Catalyst attempted to marry these differing timescales through the sprint mechanism, although admittedly the focus in the sprints was on doing things quickly: the nine month time limit clearly is biased towards the "fast" way of thinking. There was an attempt, however, to incorporate social science within the loop: the challenge for social science was to contribute by turning around insights much faster than is usual. In practice, Speedplay was the most successful way of reconciling these timescales. As noted earlier, Speedplay gives equal play to action research and agile development methods, but it does expect both to be done quickly. Applying Speedplay is incredibly intense, which has impact on the well-being of the researchers involved (see Section 4.1.3). And yet, this is our "best effort" at finding the "best of both worlds".

Given these differences in speed and time, some disciplines most naturally work better together than others. Design and computer science are obvious bedfellows. Both believe in rapid prototyping, quick reflection, and iterative improvements. These are in stark conflict with qualitative methods in social science.

Academics can be selfish towards their own research niche. Let us qualify this statement. Whilst every academic involved in Catalyst had a desire for projects to succeed and to really have an impact on society, the system within which they operate mandates that they protect themselves in a number of ways. In reality, this means that academics are internally conflicted: as a simple case, they may try, for example, to immerse themselves in and understand a foreign discipline, but they ultimately are rewarded for publishing in their own discipline, which means that at some point they must withdraw from the more selfless aspects of research, and do what is required of them for promotion, career development, or even simply to keep their job.

From the beginning in Catalyst, it was recognized that special consideration would be needed to encourage and support academics to step outside of their discipline and engage in what was somewhat risky community-University research. During the bid preparation process, the strategy for this was to explicitly cost in time for academics that would allow them to take part. Each Catalyst project, therefore, when preparing its budget, was asked to include percentage FTE for the academic staff. The idea was that if an academic was costed in at a certain percentage, this would be taken into account by their Head of Department when allocating teaching duties, and so the academic would receive a lighter teaching load to allow them to take part in Catalyst.

In reality, this mechanism was ineffective, for two reasons. Firstly, University processes are not responsive enough to take into account allocated percentages on short term projects like those in Catalyst. Typically, Catalyst opened up applications for projects, and it took a matter of just a month or two between when an application was submitted and when the project started. Once started, the project duration was nine months maximum. However, teaching allocation processes work on an annual cycle, so, in practice, the teaching allocations during when a particu- 
lar Catalyst project took place would have already been decided, and could not be changed at short notice. Some academics managed to get future credit for Catalyst time: their Head of Department agreed to include the percentage time in the following year's allocation. But, more generally, the procedures for allocating teaching, and the extent to which grant time is taken into account, differs widely in different departments. This makes it difficult for a project like Catalyst to incentivise academic participation when the models for incentivisation are wildly different across the disciplines.

Secondly, and, more importantly, academics do not get involved in projects because some of their time is allocated for it. They do not "work to order" so to speak. Rather, academics get involved with something if it is intellectually and/or personally stimulating. Academics are over-worked anyway, so a modest (say) $10 \%$ allocation in a workload allocation model will make little practical difference to their workload. This aspect played out in Catalyst as follows. Academics would sometimes get involved in Catalyst projects, but then withdraw at some later stage. This happened because of the co-design nature of the projects: at the beginning of a co-design project, all ideas are on the table, and so it is easy for academics to engage, knowing their personal academic interests are "in the mix"; however, at some stage, the decision to focus is made and this invariably will not match all of the academics' research interests. Some academics (the selfless ones!) will continue to engage, knowing that they can still make some contribution to the overall project. Others, however, make a decision to disengage at this point, realizing that the project will not result in publications in their area of interest, will not further their careers, or can no longer be justified to their Department. Whilst we in no way wish to imply that academics are purely Machiavellian creatures, driven only by an egotistical need to publish and be recognized, there is some truth to the fact that the academic system rewards individual achievement over group collaboration, and the latter is the fundamental underlying principle of community-University partnership projects.

University structures promote cross-discipline competition not collaboration. In a similar way, Universities, although nowadays they universally promote crossdisciplinary research, are often not set up for it. The Faculty structure of UK universities, for example, creates clear boundaries between the physical and social sciences. These boundaries can sometimes be hard to cross because Faculties, and within them Departments, compete internally for University recognition and resources. University Departments are evaluated partly on the research income they generate and so a question arises for any cross-disciplinary initiative, which is how to divide the research income from a project across Departments. This has very immediate ramifications since those Departments then compete with each other, partly according to research income, for future investment. Some universities, of course, promote cross-disciplinarity more than others. Cross-disciplinary centres can alleviate the problems of competition to a certain extent. However, there remains something deeply culturally embedded at all levels of academe that encourages each discipline to consider itself "better" than the others. This manifests itself every day at committee meetings across the University where Departments are asked to report 
on various metrics of success, and then those metrics are implicitly or explicitly compared with other Departments.

We believe that strong community-University partnerships can only flourish when this kind of competitive culture is actively broken down in favour of a more collaborative style of working. In Catalyst, for example, which initially involved six Lancaster University Departments, great pain was taken to allocate research income equitably across the Departments. The School of Computing and Communications was the lead partner, and so could have decided to take the lion's share of the expenditure. However, it was decided early on to apportion all research income and expenditure pro rata across Departments according to the named academic staff from those Departments involved in Catalyst. Whilst this created an administrative overhead - and one which the University was not set up for - it did go some way to promote Catalyst as properly equitable when dealing across disciplines.

\subsection{Practicalities}

We finish this section by briefly reflecting on some of the very practical considerations of a cross-disciplinary community-University research project such as Catalyst. Some of these have already been touched upon - such as the lack of procedures for apportioning research income across Departments for projects where this is no single cost centre. In short, there are a whole plethora of logistical challenges that must be navigated or created for a large community-University partnership such as Catalyst. It is difficult to generalize as to the current logistical support for community-University partnership projects within Universities as a whole. We limit our discussion here, therefore, to some of the major challenges we faced at our own university, while accepting that other universities may already have better (or indeed worse) procedures in place.

The main point we wish to make in this section is the need for clear policies and procedures to be in place in community-University research projects. Whereas many research projects - even large, collaborative ones - can "get away" with a light touch in terms of documentation of procedures and processes, this is not possible in community-University partnerships. We have already emphasized the need to manage expectations both on the University and community side. In addition to this, there needs to be clarity in all aspects of how the project is managed. The community groups are external entities, who will not necessarily have an understanding of the idiosyncratic ways that universities operate, and their continued engagement with the University is largely driven by the nature of their experience with it.

Catalyst involved a number of activities which required clear policies and procedures to be put in place: the grant application process, subcontracts with community groups, expectations on the form and nature of project outputs, transparency in paying expenses for community representatives, project governance, etc. Fortunately, this complex arrangement of activities and procedures can be navigated relatively simply by remembering a single key principle: transparency. As with all initiatives 
where external parties are involved, and are asked to participate, any policy should be defined, driven and monitored according to its transparency. Catalyst made every attempt, at all stages of the project, to follow such a principle.

Whilst these efforts at being fair and transparent at all times were largely successful, there were cases where Catalyst had to either circumvent the system or faced unsurmountable barriers from the system. One of these relates to how community organisations were remunerated for their participation. As mentioned in Section 4.1, the original Catalyst bid included funds for paying community expenses but not for paying community members for their time. This oversight was quickly rectified, but it was not immediately clear how community members could be paid. Research money is usually used to pay research staff, employed by a University. The solution was that the community members were viewed as temporary research staff and then a variety of methods had to be used to employ them. Depending on what was best for a particular individual, some were employed on short-term University contracts, some were paid as consultants, and some organisations were sub-contracted. None of these arrangements was new or unusual in of itself, but the need to pay particular attention to the sensitivities of each community organisation, and the need to design a solution that worked for them, did require a lot of time and effort on the part of University administrative staff.

A more serious barrier arose in the follow-on funding of one of the Catalyst launchpads, Local Trade. This project was a collaboration between a local social enterprise, promoting local trading cultures as a way to improve community cohesion, and academics from design and computing. The project was initially funded as a Catalyst launchpad by the end of which a tool had been developed which aimed to track people's spending behaviours and present visualisations showing the percentage of local versus non-local trades and the benefits to the local economy of higher local trade percentages (Figure 5). The project was successful as a Catalyst launchpad, producing a digital prototype with strong commitment from a local social enterprise that was intent on taking the project forward towards real-world use. However, the project was still in its early stages, and so the partners decided to apply for further research funding from EPSRC's Research In The Wild programme to further evaluate and test the technology. They were successful in doing so. However, a problem immediately presented itself.

The Research in the Wild programme is set up to encourage real-world deployments of digital innovations where end-users work in partnership with universities. This is exactly what the Local Trade partnership was about. Unfortunately, there was a stipulation in the funding call that partners could not receive any monies. Presumably, this was in place to avoid research funding being given to for-profit companies. However, for social enterprises, as was the case in Local Trade, or charities/community groups as partners, this constraint presented a real barrier to the research going forward. In the case of Local Trade, the social enterprise simply had to accept that whilst the University would receive around $£ 200 \mathrm{~K}$ in additional funding, the social enterprise, who was an equal partner from the start, would receive nothing. We have seen other similar calls from research funders that also prevent funding going outside the University system. There is clearly a case to review such 
policies: research councils are actively pushing academics to evidence more impact from their research, and yet, they sometimes put barriers in place to making this realizable in practice.

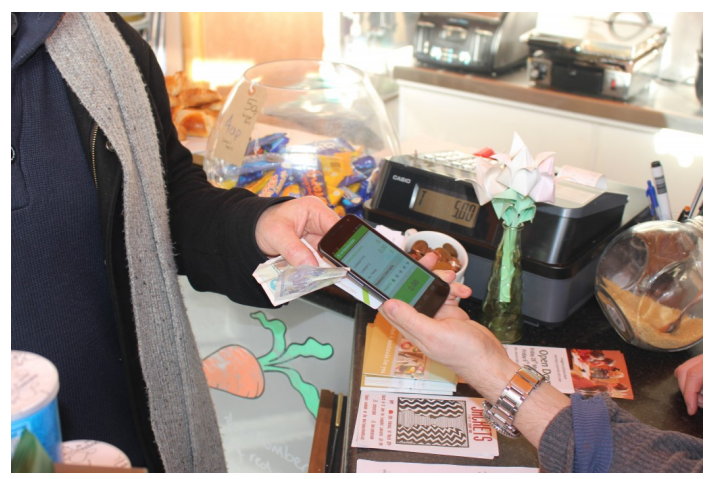

Fig. 5 The Local Trade launchpad (which has since evolved into BARTER: barterproject.org).

\section{Conclusions}

Acknowledgements If you want to include acknowledgments of assistance and the like at the end of an individual chapter please use the acknowledgement environment - it will automatically render Springer's preferred layout.

\section{References}

1. Chamberlain, A., Crabtree, A., Rodden, T., Jones, M. and Rogers, Y.: Research in the Wild: Understanding "in the wild" approaches to design and development. In Conference on Designing Interactive Systems, pp. 795-796 (2012)

2. Brown, B., Reeves, S. and Sherwood, S.: Into the wild: challenges and opportunities for field trial methods. In the ACM CHI Conference on Human Factors in Computing Systems, pp. 1657-1666 (2011)

3. Johnson, R., Rogers, Y., van der Linden, J., Bianchi- Berthouze, N.: Being in the thick of in-the-wild studies: the challenges and insights of researcher participation. In the ACM CHI Conference on Human Factors in Computing Systems, pp. 1135-1144 (2012)

4. Crabtree, A., Chamberlain, A., Grinter, R., Jones, M., Rodden, T. and Rogers, Y.: The Turn to The Wild, Special Issue of ACM Transactions on Computer-Human Interaction (TOCHI), 20(3) (2013)

5. Hayes, G. R.: The relationship of action research to human-computer interaction. ACM Transactions on Computer-Human Interaction (TOCHI), 18(3), Article number 15 (2011)

6. Kensing, F.: Methods and Practices in Participatory Design. ITU Press, Copenhagen, Denmark (2003)

7. Heron, J.: Co-operative Inquiry: Research into the Human Condition, Sage, London (1996) 
8. Sanders, E., Stappers, P. J.: Co-creation and the new landscapes of design. Co-Design 4(1), pp. 5-18 (2008)

9. Kyng, M.: Bridging the Gap Between Politics and Techniques: On the next practices of participatory design. Scandinavian Journal of Information Systems, 22(1), pp. $49-67$ (2010)

10. Steen, M.: Tensions in human-centred design. CoDesign, 7(1), pp. 45-60 (2011)

11. Baum, F., MacDougall, C. and Smith, D.: Participatory action research, Journal of epidemiology and community health, 60(10), pp. 854-7 (2006)

12. Walter, M.: Participatory Action Research. In M. Walter, ed. Social Research Methods. South Melbourne: Oxford, pp. 1-8 (2009)

13. Susman, G.I. and Evered, R.D.: An Assessment of the Scientific Merits of Action Research, Administrative Science Quarterly, (23), pp. 582-603 (1978).

14. Reason, P.: Integrating Action and Reflection Through Co-Operative Inquiry, Management Learning, 30(2), pp. 207-225 (1999)

15. Bendapudi, N. and Leone, R.P.: Psychological Implications of Customer Participation in CoProduction. The Journal of Marketing, 67(1), pp. 14-28 (2003)

16. Duret, M., Martin, S., Latour, B., Bischof, H., Reyse, S., Sondermann, K., Oroben-goa, A., Bijket, W., Hommels, A., Peters, P., Laredo, P., Woolgar, S., McNally, R. and Janssens de Bisthoven, O.: PROTEE: procedures dans les transportes d'evaluation et de suivi des innovations considerees comme des experimentations collectives, Final Report for Publication, European Commission, Brussels, Belgium (2000)

17. Valve, H.R., McNally, R.: Articulating scientific policy advice with PROTEE, Sci. Technol. Hum. Values 38(4), pp. 470-491 (2013)

18. Ferrario, M-A., Simm, W., Newman, P., Forshaw, S., Whittle, J.: Software engineering for social good: integrating action research, participatory design, and agile development. In International Conference on Software Engineering (ICSE), pp. 520-523, (2014)

19. Kera, D.: Hackerspaces and DIYbio in Asia: connecting science and community with open data, kits and protocols, Journal of Peer Production, Issue \#2, pp. 1-8 (2012)

20. Gould, J. and Lewis, C.: Designing for Usability : Key Principles and What Designers Think. Communications of the ACM, 28(3), pp. 300-311 (1985)

21. Sharp, H., Robinson, H. and Segal, J.: Integrating User-Centered Design and Software Engineering: A Role for Extreme Programming? Presentation available from www.ics.heacademy.ac.uk/

22. Fox, D., Sillito, J. and Maurer, F.: Agile Methods and User-Centered Design: How These Two Methodologies are Being Successfully Integrated in Industry. Agile Conference, pp. 63$72(2008)$

23. Larman, C.: Agile and iterative development: a manager's guide. Addison-Wesley Professional (2004)

24. Murray, A.: Managing successful projects with PRINCE2. Stationery Office Books (2009)

25. Boehm, B., and Turner, R.: Balancing agility and discipline: Evaluating and integrating agile and plan-driven methods. 26th International Conference on Software Engineering (ICSE), pp. 718-719 (2004)

26. Boehm, B.: A spiral model of software development and enhancement. Computer, 21(5), pp. 61-72 (1988)

27. Muller, M.J.: Participatory design: the third space in HCI, Human-Computer Interaction: Development Process, pp. 165-185 (2003)

28. Ehn, P.: Participation in design things. In Proceedings of the Tenth Anniversary Conference on Participatory Design, pp. 92-101 (2008)

29. Acosta, R., Burns, C., Rzepka, W., and Sidoran, J.: Applying Rapid Prototyping Techniques in the Requirements Engineering Environment, In International Conference on Requirements Engineering, pp. 66-74, (1994)

30. Hand, E.: Citizen Science: People Power, Nature, 466(7307), pp. 685-687 (2010)

31. Whittle, J.: How Much Participation is Enough? A Comparison of Six Participatory Design Projects in Terms of Outcomes, In Participatory Design Conference (2014)

32. Holmes, T., Blackmore, E., Hawkins, R., Wakeford, T.: The Common Cause Handbook (2012). 
33. Knobel, C.P. and Bowker, G.C.: Values in design. Commun. ACM 54(7), pp. $26-28$ (2011)

34. Simm, W., Ferrario, M-A., Gradinar, A., Whittle, J.: Prototyping Clasp: implications for designing digital technology for and with adults with autism, In Designing Interactive Systems (DIS), pp. 345-354 (2014)

35. Grinbaum, A. and Groves, C.: What is "Responsible" about Responsible Innovation? Understanding the Ethical Issues. In R. Owen, M. Heintz, and J. Bessant (Eds.), Responsible Innovation. Chichester, UK: Wiley.

36. Von Schomberg, R. (Ed.): Towards Responsible Research and Innovation in the Information and Communication Technologies and Security Technologies Fields. Luxembourg: Publication Office of the European Union (2011)

37. http://responsible-innovation.org.uk/torrii/

38. Wilson, L. and Blackwell, A.F.: Interdisciplinarity and Innovation. In E.G. Carayannis (ed). Encyclopedia of Creativity, Invention, Innovation and Entrepreneurship. Springer, pp. 10971104 (2013)

39. Nissan, M.: Ten Cheers for Interdisciplinarity: the Case for Interdisciplinary Knowledge and Research. The Social Science Journal, 34(2), pp. 201-216 (1997)

40. Hacklina, F. and Wallina, M.W.: Convergence and interdisciplinarity in innovation management: a review, critique, and future directions. The Service Industries Journal, 33(7-8), pp. 774-788 (2013)

41. Ferrario, M.A., Forshaw, S., Newman, P., Simm, W., Friday, A. and Dix, A.: On the edge of supply: designing renewable energy supply into everyday life. Proceedings of ICT4Sustainability, 2nd International Conference (2014) 